\title{
Workplace Social Capital and All-Cause Mortality: A Prospective Cohort Study of 28043 Public-Sector Employees in Finland
}

\section{Citation}

Oksanen, Tuula, Mika Kivimäki, Ichiro Kawachi, S. V. Subramanian, Soshi Takao, Etsuji Suzuki, Anne Kouvonen, et al. 2011. "Workplace Social Capital and All-Cause Mortality: A Prospective Cohort Study of 28043 Public-Sector Employees in Finland." American Journal of Public Health 101 (9): 1742-48. https://doi.org/10.2105/ajph.2011.300166.

\section{Permanent link}

http://nrs.harvard.edu/urn-3:HUL.InstRepos:41275472

\section{Terms of Use}

This article was downloaded from Harvard University's DASH repository, WARNING: This file should NOT have been available for downloading from Harvard University's DASH repository.

\section{Share Your Story}

The Harvard community has made this article openly available.

Please share how this access benefits you. Submit a story.

Accessibility 


\section{Workplace Social Capital and All-Cause Mortality: A Prospective Cohort Study of 28043 Public-Sector Employees in Finland}

| Tuula Oksanen, MD, PhD, Mika Kivimäki, PhD, Ichiro Kawachi, MD, PhD, S. V. Subramanian, PhD, Soshi Takao, MD, PhD, Etsuji Suzuki, MD, PhD, Anne Kouvonen, PhD, Jaana Pentti, MSc, Paula Salo, PhD, Marianna Virtanen, PhD, and Jussi Vahtera, MD, PhD

In the past 2 decades, interest has grown in the health effects of social capital, defined as the features of social structures, such as levels of interpersonal trust and norms of reciprocity and mutual aid, that act as resources for individuals and facilitate collective action. ${ }^{1-3}$ In the literature, social capital has been conceptualized (and measured) both at the individual level and at the group level. ${ }^{4,5}$ At the individual level, the most common approach has been to measure individual perceptions of the level of cohesion or solidarity in the group to which the individual belongs. At the group level, the focus is on the collective (e.g., neighborhood or workplace). Thus, a common practice has been to aggregate the individual responses from surveys to the collective. Some authors have also measured social capital through objective indicators that are not dependent on respondent perceptions, such as density of civic associations within a community. ${ }^{6}$ Another approach derives measures of social capital from social network analysis. $^{7}$

Adding to cross-sectional ecological analyses, ${ }^{8}$ at least 7 prospective studies in nonoccupational settings have examined the association between social capital and mortality among the working-aged population through at least 1 indicator of social capital. ${ }^{9-15}$ Findings from those studies have been mixed, although the preponderance of evidence favors a weak inverse association.

Several factors may have contributed to inconsistent evidence. For example, previous studies on mortality have focused on social capital in residential or geographical areas rather than in occupational settings, although recent research has emphasized the importance of the evaluation of workplace social capital to explain variations in employees' health. ${ }^{16-19}$ Indeed, for working populations, sources of variation in social capital are likely to

Objectives. We examined the association between workplace social capital and all-cause mortality in a large occupational cohort from Finland.

Methods. We linked responses of 28043 participants to surveys in 2000 to 2002 and in 2004 to national mortality registers through 2009. We used repeated measurements of self- and coworker-assessed social capital. We carried out Cox proportional hazard and fixed-effects logistic regressions.

Results. During the 5-year follow-up, 196 employees died. A 1-unit increase in the mean of repeat measurements of self-assessed workplace social capital (range 1-5) was associated with a $19 \%$ decrease in the risk of all-cause mortality (age- and gender-adjusted hazard ratio $[\mathrm{HR}]=0.81 ; 95 \%$ confidence interval $[\mathrm{Cl}]=0.66,0.99$ ). The corresponding point estimate for the mean of coworkerassessed social capital was similar, although the association was less precisely estimated (age- and gender-adjusted $\mathrm{HR}=0.77 ; 95 \% \mathrm{Cl}=0.50,1.20$ ). In fixedeffects analysis, a 1-unit increase in self-assessed social capital across the 2 time points was associated with a lower mortality risk (odds ratio $=0.81 ; 95 \% \mathrm{Cl}=0.55$, 1.19).

Conclusions. Workplace social capital appears to be associated with lowered mortality in the working-aged population. (Am J Public Health. 2011;101: 1742-1748. doi:10.2105/AJPH.2011.300166)

be found in settings where people spend an increasing portion of their daily lives: workplaces. ${ }^{20,21}$ Furthermore, because all these studies assessed social capital at only 1 time point, further data with repeated measurements of social capital are needed to strengthen the evidence.

The Finnish Public Sector Study had at least 3 strengths that addressed the question of workplace social capital and mortality. First, it provided unique individual- and workplacelevel survey data from a large occupational cohort linked to comprehensive national mortality registers. The linkage was complete, minimizing any bias related to selective sample retention. Second, the data included repeated assessments of workplace social capital, which enabled the determination of both repeated exposure and change in workplace social capital. Third, both self- and coworker-assessed social capital were available. This information helped to address reporting bias. We used these data to examine the hypothesis that repeated exposure to low workplace social capital and adverse changes in social capital are associated with increased mortality, corresponding to previous findings on workplace social capital and self-rated health and depression, ${ }^{22}$ important correlates of all-cause mortality. ${ }^{23}$

\section{METHODS}

The Finnish Public Sector Study comprised all employees working in the service of 10 towns and 21 hospitals in Finland. ${ }^{24}$ The employers' records were used to identify the eligible populations for surveys and the work unit code for each employee. A total of 48598 employees responded (response rate $=68 \%$ ) to the first survey in 2000 to 2002 (time 1). Of these respondents, 36440 were alive and still employed in the target organizations at the time of the second survey in 2004 (time 2), and 29180 responded (response rate $=80 \%$ ). 
Personal identification codes, which are assigned to all citizens in Finland, linked respondents to their records in national health and death registers. For all participants, the linkage to registers was 100\% complete; thus no sample attrition occurred during follow-up.

Our analyses were restricted to 28043 employees (82\% female, aged 20-66 years) with complete data on workplace social capital measured in both surveys and who were alive at the beginning of the follow-up, January 1 , 2005. The study cohort did not substantially differ from those excluded at baseline in mean social capital (3.60 in the sample vs 3.57 in those excluded), mean age (45.8 vs 45.5 years), proportion of women ( $82 \%$ vs $79 \%$ ), socioeconomic status (SES; 18\% manual workers vs $19 \%$ ), or presence of chronic illness at baseline $(12.4 \%$ vs $14.5 \%)$. Mortality was lower in the study cohort than among the nonparticipants (0.7\% vs $1.4 \%)$.

We used participants' personal identification numbers to collect data on overall mortality from the Statistics Finland register, which provides virtually complete population-level mortality data. We obtained the date of death for all participants who died between January 1, 2005, and December 31, 2009.

\section{Workplace Social Capital}

We used an 8-item measure specifically designed to measure workplace social capital (Appendix A, available as a supplement to the online version of this article at http://www. ajph.org). ${ }^{25}$ Previous psychometric evaluation has demonstrated the scale to be reliable and valid. The internal consistency of the scale was high (Cronbach's $\alpha=0.88$ ), and the $r_{\text {wg }}$ index $(0.88)$ indicated significant within-unit agreement.

For each participant, we averaged the scores of the items in the first survey and the second survey. We treated the workplace social capital scores (time 1 and time 2) as a continuous variable, with a higher value indicating higher social capital. To assess repeated exposure to workplace social capital, we calculated the mean of the scores from the 2 surveys. As previously, ${ }^{17,18}$ we also measured coworkers' perceptions of social capital in the respondent's work unit (excluding self-assessment) to address potential reporting bias, that is, the participant's characteristics influencing the assessment of social capital.
We used employers' work unit administrative registers to select work units at the lowest organizational level. These functional work units were typically at a single location (e.g., a kindergarten, a school, or a hospital ward). We excluded from analysis individuals employed in work units with fewer than 3 respondents, because by definition social capital is accumulated by virtue of a membership in a group.

\section{Covariates}

Demographic characteristics obtained from employers' registers at study entry (time 1) were participants' age, gender, and SES, derived from the occupational title classification of Statistics Finland $^{26}$ : upper-grade nonmanual workers (e.g., teachers, physicians), lower-grade nonmanual workers (e.g., registered nurses, technicians), and manual workers (e.g., cleaners, maintenance workers). Marital status was taken from a survey item (married or cohabiting vs other).

Health risk behaviors, assessed in both surveys, were current smoking status (smoker vs nonsmoker), high alcohol consumption (average weekly consumption $\geq 210 \mathrm{~g}$ of absolute alcohol), ${ }^{27}$ leisure-time physical inactivity $(<2.0$ metabolic equivalent task hours/day, corresponding to approximately 30 minutes of walking), ${ }^{28}$ and obesity (body mass index, defined as weight in kilograms divided by height in meters squared, $\geq 30 \mathrm{~kg} / \mathrm{m}^{2}$ ).

Health indicators, derived from survey responses, were psychological distress, measured by a 12 -item version of the General Health Questionnaire (scores $\geq 4$ indicated psychological distress), ${ }^{29}$ and suboptimal self-rated health (average or worse vs good or very good health). We obtained data on antidepressant use from the national Drug Prescription Register kept by the Social Insurance Institution of Finland. In Finland, all residents are covered by the National Health Insurance Scheme, which pays at least part of the costs of all filled prescriptions. Data on dates of purchases of all drugs in the World Health Organization's Anatomical Therapeutic Chemical (ATC) Classification ${ }^{30}$ and the corresponding defined daily dosages can be traced from the national pharmacy records. We defined antidepressant use as the annual purchase of antidepressants (ATC code NO6A) of at least 30 daily doses during the survey year. In 1 town, the copayment for medicine costs was covered by the employer during employment, and therefore employees' purchases could not be traced from the pharmacy records. We did not exclude these employees from the analyses but categorized them as nonusers. We calculated, from the estimates of antidepressant use in the whole sample, that approximately $0.7 \%$ of antidepressant users in the study were consequently misclassified.

Data on chronic somatic illness came from the Drug Reimbursement Register, which contains information on persons entitled to special reimbursement for the treatment of chronic conditions and diseases and the date when the special reimbursement is granted. Patients who apply for special reimbursement must attach a detailed medical statement confirming the diagnosis, prepared by the treating physician We identified all participants with hypertension, cardiac failure, ischemic heart disease, diabetes, asthma or other chronic obstructive lung disease, and rheumatoid arthritis at the end of the survey year. ${ }^{31}$ In addition, we obtained data on cancer diagnosed during the survey year or 4 preceding years from the Finnish Cancer Registry, which compiles all notifications of cancers nationwide. ${ }^{32}$ We coded the presence of any of these somatic illnesses as yes or no at time 1 and time 2 .

\section{Statistical Analysis}

We used analysis of variance to examine the differences in the mean workplace social capital scores from the 2 surveys as a function of the cohort characteristics. We analyzed the association between covariates at baseline (time 1) and the outcome (all-cause mortality) with Cox proportional hazard models. To investigate the association between workplace social capital and mortality, we used 2 complementary methods: Cox regression analysis and fixed-effects models.

First, Cox proportional hazard models provided hazard ratios (HRs) and their 95\% confidence intervals (CIs) for mortality risk per 1-unit increase in mean of workplace social capital (self- and coworker-assessed from repeated surveys), adjusted for age and gender. We separately adjusted the models for covariates at time 1; that is, SES and marital status, health risk behaviors, and health indicators. The final model incorporated all these covariates. We tested the potential interactions 
between gender, SES, and the assessments of workplace social capital on all-cause mortality with the corresponding interaction terms (gender $\times$ social capital and SES $\times$ social capital) in models that incorporated the main effect. The follow-up began January 1, 2005, and ended with participants' death or on December 31, 2009, whichever came first.

To address the potential bias arising from reverse causation (decrease in workplace social capital in the second survey stemming from adverse change in health proximal to death), we carried out 2 sensitivity analyses with Cox regression analyses. First, we repeated the analyses but applied a 1-year time lag after the second survey year to exclude deaths in the early period of follow-up. Second, we estimated whether the association between workplace social capital and mortality was independent of (adverse) changes in lifestyle or health status by controlling for the health indicators at time 2 in the Cox regression analyses.

We then applied the fixed-effects method for nonrepeated events (death) through conditional logistic regression with time-discrete data. In the analysis of longitudinal data, the fixed-effects method offers the advantage of controlling for stable characteristics of the individuals, whether measured or not, by using within-individual variation only to estimate the regression coefficients. ${ }^{33}$ The disadvantage is that it may yield higher $P$ values and wider CIs. The basic requirements for using the fixed-effects method are that the independent variable-in our study, workplace social capital-must be measured on at least 2 occasions and that the variable must change in value (either increase or decrease) across 2 occasions. ${ }^{33}$ Thus, we used fixed-effects regression to model the change in social capital across survey waves in relation to mortality.

We explored the case-crossover approach by including only those who died and whose selfassessed workplace social capital changed between time 1 and time $2 .{ }^{34}$ We considered time 2 as the hazard time and time 1 as the control time and analyzed the data with matched-pair conditional logistic regression predicting death. Finally, we controlled for time-varying health indicators. The results were expressed as odds ratios (ORs) and their 95\% CIs for risk of death per 1-unit increase in workplace social capital across the 2 measurements.
All analyses were performed with SAS version 9.1.3 statistical software (SAS Institute Inc, Cary, North Carolina). We defined significance as a 2 -sided $P$ value $<.05$.

\section{RESULTS}

The characteristics of the study cohort are shown in Table 1. The mean self- and coworker-assessed social capital, measured in 2 surveys approximately 3.6 years apart, were $3.59(\mathrm{SD}=0.65)$ and 3.59 (SD=0.33), respectively. Both assessments were significantly lower among individuals with behavioral health risks and prevalent chronic illnesses, albeit in absolute terms, these differences were small. The differences between the means of self- and coworker-assessed workplace social capital mainly related to health indicators: individuals who had psychological distress or poor self-rated health or who purchased antidepressants rated their social capital lower than did their coworkers in the same work unit.

During the 5-year follow-up, 196 (0.7\%) participants died. The Cox proportional hazards model showed a strong association between mortality and current smoking and antidepressant use (Table 1). Higher mortality was also associated with male gender, manual worker status, obesity, and suboptimal selfrated health. We also found that a 1-unit increase in the mean of repeated self-assessed workplace social capital (corresponding to an $\sim 1$.5-SD change in averaged ratings) was associated with a 19\% lower risk of mortality. The HR for a 1-unit increase in social capital for risk of death was $0.81(95 \% \mathrm{CI}=0.66,0.99)$ after adjustment for age and gender (Table 2). When we entered other demographic data and health risk behaviors from time 1 into the model, the point estimate remained similar, although the 95\% CIs widened slightly and crossed the unity. Entering baseline health indicators into the model did not attenuate the association. Higher coworker-assessed workplace social capital was also associated with lower risk of death, although the association did not reach statistical significance; the corresponding age- and gender-adjusted HR was $0.77(95 \% \mathrm{CI}=0.50,1.20)$. We found no interactions between gender or SES and self- or coworker-assessed social capital for mortality (all, $P>$.1).
Results from the sensitivity analyses were consistent with the main analyses. When we applied a 1-year time lag after the second survey, the age- and gender-adjusted HR for risk of mortality per 1-unit increase in mean scores of self-assessed workplace social capital was $0.80(95 \% \mathrm{CI}=0.64,1.00)$ and in coworker-assessed social capital was 0.71 (95\% $\mathrm{CI}=0.44,1.14)$. Entering health indicators from time 2 into the model resulted in essentially similar point estimates: the HR for a 1-unit increase in self-assessed social capital was 0.84 $(95 \% \mathrm{CI}=0.68,1.03)$ and in coworkerassessed social capital was $0.78(95 \% \mathrm{CI}=$ $0.50,1.21)$.

Results from the fixed-effects models showed that the point estimates of the association between workplace social capital and mortality risk were in a similar direction to the Cox regression estimates. A 1-unit increase in social capital across the 2 time points decreased the mortality risk by $19 \%(\mathrm{OR}=0.81 ; 95 \%$ $\mathrm{CI}=0.55,1.19)$. Adjustment for changes in health indicators between the 2 time points (i.e., increase or decrease in psychological distress, self-rated health, or antidepressant use) attenuated the association $(\mathrm{OR}=0.91$; $95 \% \mathrm{CI}=0.60,1.37)$.

\section{DISCUSSION}

To our knowledge, ours was the first prospective cohort study to investigate the association between workplace social capital and all-cause mortality. Furthermore, we had the advantage of using repeated measurements of social capital, enabling us to assess the effects of repeated exposure and change in exposure to workplace social capital. Our findings suggested that exposure to high levels of social capital was associated with a lower risk of overall mortality, as hypothesized. The 2 statistical methods, the Cox regression and the fixed-effects method, as well as the findings derived from 2 different measures for the exposure, yielded consistent results. The findings of self- and coworker-assessed social capital were convergent, which lends support to the assumption that the perception of social capital at work depends not only on the perceptions of an individual but also on external working conditions and shared perceptions of workplace. Taken together, these results 
TABLE 1-Characteristics of Participants in Study of Workplace Social Capital and Mortality: Finnish Public Sector Study, 2000-2009

\begin{tabular}{|c|c|c|c|c|}
\hline Characteristic & $\begin{array}{l}\text { Participants, No. } \\
\text { (\%) or Mean } \pm \text { SD }\end{array}$ & $\begin{array}{l}\text { Self-Assessed Workplace } \\
\text { Social Capital, }{ }^{\mathrm{a}} \text { Mean } \pm \text { SD }\end{array}$ & $\begin{array}{l}\text { Coworker-Assessed Workplace } \\
\text { Social Capital, }{ }^{\text {a }} \text { Mean } \pm \text { SD }\end{array}$ & $\begin{array}{l}\text { All-Cause Mortality, } \\
\text { HR }(95 \% \text { Cl) }\end{array}$ \\
\hline Total & 28043 & $3.59 \pm 0.65$ & $3.59 \pm 0.33$ & $196(0.7)$ \\
\hline \multicolumn{5}{|c|}{ Sociodemographics } \\
\hline Age at baseline, $y^{b}$ & $45.9 \pm 8.2$ & NA & NA & $2.44(2.00,3.10)$ \\
\hline \multicolumn{5}{|l|}{ Gender } \\
\hline Women (Ref) & $23087(82)$ & $3.61 \pm 0.65$ & $3.62 \pm 0.32$ & 1.00 \\
\hline Men & $4956(18)$ & $3.52 \pm 0.67$ & $3.48 \pm 0.33$ & $1.87(1.37,2.55)$ \\
\hline \multicolumn{5}{|l|}{ Socioeconomic position } \\
\hline Upper nonmanual (Ref) & $7680(27)$ & $3.69 \pm 0.63$ & $3.63 \pm 0.34$ & 1.00 \\
\hline Lower nonmanual & $15353(55)$ & $3.58 \pm 0.64$ & $3.60 \pm 0.32$ & $0.89(0.63,1.25)$ \\
\hline Manual & $4978(18)$ & $3.51 \pm 0.70$ & $3.53 \pm 0.31$ & $1.25(0.86,1.82)$ \\
\hline \multicolumn{5}{|l|}{ Marital status } \\
\hline Married or cohabiting (Ref) & $21291(77)$ & $3.61 \pm 0.65$ & $3.60 \pm 0.33$ & 1.00 \\
\hline Other & $6464(23)$ & $3.55 \pm 0.66$ & $3.58 \pm 0.32$ & $0.76(0.56,1.05)$ \\
\hline \multicolumn{5}{|c|}{ Health-related behavior at baseline } \\
\hline \multicolumn{5}{|l|}{ Current smoker } \\
\hline No (Ref) & $22577(83)$ & $3.60 \pm 0.65$ & $3.60 \pm 0.33$ & 1.00 \\
\hline Yes & $4673(17)$ & $3.57 \pm 0.69$ & $3.58 \pm 0.33$ & $2.52(1.85,3.43)$ \\
\hline \multicolumn{5}{|l|}{ Heavy drinker (<210 g/wk) } \\
\hline No (Ref) & $25643(92)$ & $3.60 \pm 0.65$ & $3.60 \pm 0.32$ & 1.00 \\
\hline Yes & $2258(8)$ & $3.50 \pm 0.67$ & $3.53 \pm 0.34$ & $1.40(0.91,2.14)$ \\
\hline \multicolumn{5}{|l|}{ Physically inactive (<2 MET $h / d$ ) } \\
\hline No (Ref) & $21040(76)$ & $3.61 \pm 0.65$ & $3.60 \pm 0.33$ & 1.00 \\
\hline Yes & $6724(24)$ & $3.55 \pm 0.67$ & $3.58 \pm 0.32$ & $1.36(1.00,1.83)$ \\
\hline \multicolumn{5}{|l|}{ Obese $\left(\mathrm{BMI}<30 \mathrm{~kg} / \mathrm{m}^{2}\right)$} \\
\hline No (Ref) & $24428(89)$ & $3.60 \pm 0.65$ & $3.60 \pm 0.33$ & 1.00 \\
\hline Yes & $3032(11)$ & $3.54 \pm 0.68$ & $3.57 \pm 0.33$ & $1.63(1.13,2.34)$ \\
\hline \multicolumn{5}{|c|}{ Health indicators at baseline } \\
\hline \multicolumn{5}{|l|}{ Psychological distress } \\
\hline No & $21088(76)$ & $3.66 \pm 0.63$ & $3.60 \pm 0.33$ & 1.00 \\
\hline Yes & $6843(24)$ & $3.38 \pm 0.69$ & $3.58 \pm 0.33$ & $1.15(0.84,1.57)$ \\
\hline \multicolumn{5}{|l|}{ Suboptimal self-rated health } \\
\hline No & $20843(75)$ & $3.65 \pm 0.63$ & $3.60 \pm 0.33$ & 1.00 \\
\hline Yes & $6898(25)$ & $3.43 \pm 0.69$ & $3.57 \pm 0.32$ & $1.46(1.09,1.96)$ \\
\hline \multicolumn{5}{|l|}{ Antidepressant use $^{c}$} \\
\hline No & $27031(96)$ & $3.60 \pm 0.65$ & $3.60 \pm 0.33$ & 1.00 \\
\hline Yes & $1012(4)$ & $3.44 \pm 0.69$ & $3.59 \pm 0.32$ & $2.64(1.43,4.30)$ \\
\hline \multicolumn{5}{|l|}{ Chronic illness } \\
\hline No & $24569(88)$ & $3.60 \pm 0.65$ & $3.60 \pm 0.33$ & 1.00 \\
\hline Yes & $3474(12)$ & $3.56 \pm 0.67$ & $3.58 \pm 0.32$ & $1.26(0.88,1.80)$ \\
\hline
\end{tabular}

Note. $\mathrm{BMI}=$ body mass index; $\mathrm{Cl}=$ confidence interval; $\mathrm{HR}=$ hazard ratio; $\mathrm{MET}=$ metabolic equivalent task; $\mathrm{NA}=$ Not applicable. All $P$ values of differences in self-reported and co-workers' assessed workplace social capital and sample characteristics were $<.001$ except for co-workers' assessed workplace social capital and antidepressant use.

${ }^{a}$ Mean of repeat assessments at baseline and follow-up survey.

${ }^{\mathrm{b}} \mathrm{HR} / 10 \mathrm{y}$

${ }^{\mathrm{c} A n n u a l}$ purchases of antidepressants $>30$ defined daily dosages.

provide some new evidence for the impact of social capital on the variations in mortality in the context of the workplace.
Our findings accord with previous longitudinal studies in nonoccupational settings that found weak evidence of social capital predicting mortality. Six studies have reported significant or nonsignificant inverse associations between social capital and mortality. ${ }^{9-14}$ 
TABLE 2-Hazard Ratios for Workplace Social Capital and Mortality: Finnish Public Sector Study, 2000-2009

\begin{tabular}{lcccrr}
\hline Workplace Social Capital & Model 1, HR $(95 \% \mathrm{Cl})$ & Model 2, ${ }^{\mathrm{a}} \mathrm{HR}(95 \% \mathrm{Cl})$ & Model 3, ${ }^{\mathrm{b}} \mathrm{HR}(95 \% \mathrm{Cl})$ & Model 4, ${ }^{\mathrm{c}} \mathrm{HR}(95 \% \mathrm{Cl})$ & Model 5 ${ }^{\mathrm{d}}$ \\
\hline Self-assessed & $0.81(0.66,0.99)$ & $0.81(0.66,1.00)$ & $0.81(0.66,1.00)$ & $0.84(0.68,1.04)$ & $0.83(0.67,1.03)$ \\
Coworker assessed & $0.77(0.50,1.20)$ & $0.79(0.51,1.24)$ & $0.76(0.49,1.20)$ & $0.78(0.50,1.21)$ & $0.77(0.49,1.21)$ \\
\hline
\end{tabular}

Note. $\mathrm{Cl}=$ confidence interval; $\mathrm{HR}=$ hazard ratio. All models were adjusted for age and gender. HRs are for mortality per 1-unit increase in social capital (mean of assessments in 2000-2002 and 2004), derived from Cox proportional hazard models.

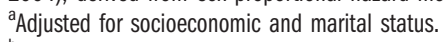

${ }^{\mathrm{b}}$ Adjusted for smoking, alcohol use, physical activity, and obesity at baseline.

${ }^{c}$ Adjusted for psychological distress, self-rated health, antidepressant prescriptions, and chronic illness at baseline.

${ }^{\mathrm{d}}$ Adjusted for all the covariates in previous models.

However, some studies have also reported nonsignificant positive associations. ${ }^{10,12,14}$ Unfortunately, the heterogeneity of the indicators of social capital used in those studies prevents further comparisons. Nonetheless, our results lend support to the view that the workplace can be at least as important a source of social capital as residential communities. ${ }^{21,35}$ Indeed, the workplace can constitute an important setting for the creation of social capital because it may encourage regular collaborative contacts among team members, and coworkers may develop a sense of community and enjoy mutual help and reciprocity in performing their jobs. ${ }^{21}$

Previous studies that examined the association of social capital and mortality predominantly assessed social capital at 1 time point only, defining the exposure as fixed. However, nearly all exposures of epidemiological interest are time varying. Thus, repeat assessment of exposure to observe changes can be important for several reasons. When the exposure (social capital) is measured only once, the findings may be attributed to misclassification bias of life course social capital. Blakely et al. partially tested this potential bias by restricting analyses to long-standing residents only. Still, no association between neighborhood social capital and mortality was detected. ${ }^{13}$

In addition, chronic diseases-including those that prove to be fatal-typically develop over a long time and thus longer-term rather than short-term exposure to a risk factor may be more relevant for disease incidence. The use of repeated measurements can contribute to understanding the explanatory power of the variables. This was demonstrated in a recent study reporting that analyses of repeated assessments of health behaviors through follow-up showed them to make a greater contribution to explaining social inequalities in mortality than when only 1 assessment was made. ${ }^{36}$

In times of ongoing changes in working life, such as mergers, outsourcing, and redundancies, only by characterizing workplace social capital with repeated measurements across time can we explore its contribution to variations in employees' health. Finally, changes in different aspects of social capital may be differently associated with changes in health. ${ }^{37}$

The potential mechanisms through which social capital may contribute to the risk of mortality have not been fully elucidated, but at least 4 plausible pathways have been suggested: health risk behaviors, dissemination of health-related information, access to local services and amenities, and psychosocial processes. $^{20}$ The mechanisms linking workplace social capital with mortality can be assumed to be similar. High workplace social capital may reinforce norms and informal (social) control over deviant health behavior to help employees to make lifestyle improvements, such as quitting smoking. ${ }^{38}$ High workplace social capital may be related to a higher degree of encouragement to influence an individual's own health, for example, to participate in physical activity, ${ }^{39}$ or it may contribute to producing positive affective states that increase motivation for self-care and protect against unhealthy behavioral coping, such as comfort eating. ${ }^{40}$

Information about healthy lifestyles and health-promoting services may diffuse more easily in workplaces characterized by high social capital $^{41}$ and help employees heed advice on health behavior, comply with preventive measures, and follow the norms of getting regular health check-ups. ${ }^{42}$ Respectful and trusting relations at work may enable employees to access resources, social support, and new information even outside their own network. ${ }^{35,43}$ High emotional, instrumental, and informational support from coworkers and reciprocity may create advantageous conditions and flexibility that increase adherence to treatment and improve the management of disease. ${ }^{21}$

Workplace social capital may also affect health indirectly through psychosocial factors. Respectful and trusting relationships at work may reduce stress and increase social support, which in turn can affect health. ${ }^{43}$ In addition, high workplace social capital may enhance people's actual control and improve their ability to solve problems. ${ }^{40,43}$ All these factors may explain the association between workplace social capital and mortality by contributing to the prevention of diseases, improved management of diseases, or increased adherence to treatment, leading to better prognosis. However, adjustment for behavioral risk factors, chronic illnesses, and other indicators of health problems did not explain the association between workplace social capital and health in our study.

\section{Strengths and Limitations}

Our study's strengths included prospective design, data from a large occupational cohort successfully linked to comprehensive population-level health and mortality registers with no loss to follow-up, repeated measurements to capture changes in workplace social capital, and a psychometrically reliable instrument in 2 surveys with sufficient response rates. In addition to self-assessment of social capital, we measured coworkers' assessment in the same work unit to reduce the possibility of reverse causation, that is, poor health influencing the 
ratings, as an explanation to our findings. In addition to the Cox regression models, we used fixed-effects regression, which accounted for all the observed and unobserved variables that were constant over time, thereby controlling for potential omitted time-invariant variables that could confound the association.

Reverse causation and confounding attributable to unmeasured factors are always possible with observational data. The association of coworker-assessed social capital and mortality did not reach statistical significance, although the point estimate was in the same direction and of similar magnitude as the results from self-assessments. In observational cohort mortality studies with prolonged periods of exposure, it is not uncommon for risk factors for death (e.g., employment status) to be determinants of subsequent exposure (referred to as the healthy worker effect). ${ }^{44}$ In such a case, however, standard analyses may underestimate the true effect of cumulative exposure on mortality. ${ }^{45}$ Avoiding this limitation would require, for example, the use of marginal structural models, ${ }^{45}$ which might be applicable in future studies of this cohort.

We introduced a time lag of 1 year in the sensitivity analyses to avoid nondiagnosed severe underlying diseases to explain the results, and the findings were consistent with the main results. Still, although we performed multiple adjustments and used the fixed-effects method to control for individual unmeasured factors, the possibility of residual confounding cannot be ruled out in observational studies such as ours. Considerable attrition occurred in the study sample, and we found that mortality was lower in the study cohort than among the nonparticipants. If sample attrition was nonrandom for exposure and was related to poor health, this could have led to an underestimation or overestimation of the association. However, we observed no substantial differences in workplace social capital scores. Therefore, we assume that attrition had no major effect on our findings.

Although our sample of employees was large, we had a limited number of deaths. Further follow-up in this aging cohort would provide more statistical power to test the associations. We measured workplace social capital only in work units. Thus, our analyses did not take into account variations in social capital across different organizational levels, such as work units within departments or departments within an organization or social capital accrued outside of work. Finally, the study cohort consisted of public-sector workers, mainly women; this may limit the generalizability of our results to other industries.

\section{Conclusions}

Previous studies revealed the association between several work-related psychosocial characteristics and mortality. ${ }^{46}$ Our study provides novel evidence of a less studied factor, workplace social capital. A variety of analytical techniques showed that low workplace social capital may be a contributing factor to employee mortality. Further research is needed to provide insight into the mechanisms underlying the association.

Further research should also focus on causes of death to determine whether the observed associations were driven by a relationship of social capital with specific fatal diseases. If the observed associations were causal, then improving workplace social capital could be a potential avenue for workplace health promotion. However, large-scale intervention studies are needed to confirm or refute this hypothesis.

\section{About the Authors}

At the time of the study, Tuula Oksanen, Ichiro Kawachi, and S. V. Subramanian were with the Department of Society, Human Development, and Health, Harvard School of Public Health, Boston, MA. Mika Kivimäki, Jaana Pentti, Paula Salo, Marianna Virtanen, and Jussi Vahtera were with the Finnish Institute of Occupational Health, Helsinki, Finland. Soshi Takao and Etsuji Suzuki were with the Department of Epidemiology, Okayama University Graduate School of Medicine, Dentistry, and Pharmaceutical Sciences, Okayama, Japan. Anne Kouvonen was with the Institute of Work, Health, and Organisations, University of Nottingham, Nottingham, UK.

Correspondence should be sent to Tuula Oksanen, Finnish Institute of Occupational Health, Lemminkäisenkatu 14-18 B, 20520 Turku, Finland (e-mail: tuula. oksanen@ttl.fi). Reprints can be ordered at http://www. ajph.org by clicking the "Reprints/Eprints" link.

This article was accepted January 8, 2011.

\section{Contributors}

T. Oksanen, J. Pentti, and J. Vahtera conceptualized and designed the study. T. Oksanen performed the statistical analysis and wrote the first draft of the article. All authors contributed substantially to interpreting the data and revising drafts of the article, and they approved the final version.

\section{Acknowledgments}

The Finnish Public Sector study was supported by the Academy of Finland (projects 117604, 124271,
124322, and 129262) and the participating organizations. Tuula Oksanen was supported by the Finnish Work Environment Fund (project 110021). Mika Kivimäki was supported by the Bupa Foundation and the New European Union Occupational Safety and Health European Research Area program. S. V. Subramanian was supported by the National Institutes of Health Career Development Award (award NHLBI 1 K25 HL081275). Anne Kouvonen was supported by a grant from the Economic and Social Research Council (grant RES-00022-3489).

\section{Human Participant Protection}

This study was approved by the ethics committee of the Finnish Institute of Occupational Health.

\section{References}

1. Bourdieu P. The forms of capital. In: Richardson J, ed. Handbook of Theory of Research for the Sociology of Education. New York, NY: Greenwood Press; 1986:241258.

2. Putnam RD. Making Democracy Work: Civic Traditions in Modern Italy. Princeton, NJ: Princeton University Press; 1993

3. Kawachi I, Kennedy BP, Lochner K, Prothrow-Stith D. Social capital, income inequality, and mortality. Am J Public Health. 1997;87(9):1491-1498.

4. Kawachi I, Subramanian SV, Kim D. Social Capital and Health: A Decade of Progress and Beyond. In: Kawachi I, Subramanian SV, Kim D, eds. Social Capital and Health. New York, NY: Springer; 2008:1-28.

5. Kawachi I. Social capital and health. In: Bird CE, Conrad P, Freemont AM, Timmerman S, eds. Handbook of Medical Sociology. Nashville, TN: Vanderbilt University Press; 2010:18-32.

6. Scheffler RM, Brown TT, Syme L, Kawachi I, Tolstykh I, Iribarren C. Community-level social capital and recurrence of acute coronary syndrome. Soc Sci Med. 2008;66(7):1603-1613.

7. Lakon CM, Godette DC, Hipp JR. Network-based approaches for measuring social capital. In: Kawachi I, Subramanian SV, Kim D, eds. Social Capital and Health. New York, NY: Springer; 2008:63-82.

8. Kim D, Subramanian SV, Kawachi I. Social capital and physical health. A systematic review of the literature. In: Kawachi I, Subramanian SV, Kim D, eds. Social Capital and Health. New York, NY: Springer; 2008:139-190.

9. Bygren LO, Konlaan BB, Johansson SE. Attendance at cultural events, reading books or periodicals, and making music or singing in a choir as determinants for survival: Swedish interview survey of living conditions. BMJ. 1996;313(7072):1577-1580.

10. Dalgard OS, Lund Håheim L. Psychosocial risk factors and mortality: a prospective study with special focus on social support, social participation, and locus of control in Norway. J Epidemiol Community Health. 1998;52(8):476-481.

11. Blomgren J, Martikainen P, Mäkelä P, Valkonen T. The effects of regional characteristics on alcohol-related mortality-a register-based multilevel analysis of 1.1 million men. Soc Sci Med. 2004;58(12):2523-2535.

12. Mohan J, Twigg L, Barnard S, Jones K. Social capital, geography and health: a small-area analysis for England. Soc Sci Med. 2005;60(6):1267-1283. 
13. Blakely T, Atkinson J, Ivory V, Collings S, Wilton J, Howden-Chapman P. No association of neighbourhood volunteerism with mortality in New Zealand: a national multilevel cohort study. Int J Epidemiol. 2006;35(4): 981-989.

14. Hyyppä MT, Mäki J, Impivaara O, Aromaa A. Individual-level measures of social capital as predictors of all-cause and cardiovascular mortality: a populationbased prospective study of men and women in Finland. Eur J Epidemiol. 2007;22(9):589-597.

15. Islam MK, Gerdtham U-G, Gullberg B, Lindström M, Merlo J. Social capital externalities and mortality in Sweden. Econ Hum Biol. 2008;6(1):19-42.

16. Oksanen T, Kouvonen A, Vahtera J, Virtanen M, Kivimäki M. Prospective study of workplace social capital and depression: are vertical and horizontal components equally important? J Epidemiol Community Health. 2010; 64(8):684-689.

17. Oksanen T, Kouvonen A, Kivimäki M, et al. Social capital at work as a predictor of employee health: multilevel evidence from work units in Finland. Soc Sci Med. 2008;66(3):637-649.

18. Kouvonen A, Oksanen T, Vahtera J, et al. Low workplace social capital as a predictor of depression: the Finnish Public Sector Study. Am J Epidemiol. 2008; 167(10):1143-1151.

19. Suzuki E, Takao S, Subramanian SV, Komatsu H, Doi H, Kawachi I. Does low workplace social capital have detrimental effect on workers' health? Soc Sci Med. 2010; 70(9):1367-1372.

20. Kawachi I, Kennedy BP, Glass R. Social capital and self-rated health: a contextual analysis. Am J Public Health. 1999;89(8):1187-1193.

21. Putnam RD. Bowling Alone: The Collapse and Revival of American Community. New York, NY: Simon \& Schuster; 2000.

22. Zheng D, Macera CA, Croft JB, Giles WH, Davis D, Scott WK. Major depression and all-cause mortality among White adults in the United States. Ann Epidemiol. 1997;7(3):213-218

23. Idler EL, Benyamini Y. Self-rated health and mortality: a review of twenty-seven community studies. $J$ Health Soc Behav. 1997;38(1):21-37.

24. Oksanen T, Kivimäki M, Pentti J, Virtanen M, Klaukka T, Vahtera J. Self-report as an indicator of incident disease. Ann Epidemiol. 2010;20(7):547-554.

25. Kouvonen A, Kivimäki M, Vahtera J, et al. Psychometric evaluation of a short measure of social capital at work. BMC Public Health. 2006;6:251.

26. Classification of Occupations. Helsinki, Finland: Statistics Finland; 1987.

27. Rimm EB, Williams P, Fosher K, Criqui M, Stampfer MJ. Moderate alcohol intake and lower risk of coronary heart disease: meta-analysis of effects on lipids and haemostatic factors. BMJ. 1999;319(7224):15231528.

28. Kujala UM, Kaprio J, Sarna S, Koskenvuo M. Relationship of leisure-time physical activity and mortality: the Finnish twin cohort. JAMA. 1998;279(6):440-444.

29. Goldberg D, Williams P. A User's Guide to the General Health Questionnaire. Berkshire, UK: NFER-Nelson; 1988.
30. Guidelines for ATC Classification and DDD Assignment. Oslo, Norway: World Health Organization Collaborating Centre for Drug Statistics Methodology; 2004.

31. Sjösten N, Vahtera J, Salo P, et al. Increased risk of lost workdays prior to the diagnosis of sleep apnea. Chest. 2009;136(1):130-136.

32. Teppo L, Pukkala E, Lehtonen M. Data quality and quality control of a population-based cancer registry. Experience in Finland. Acta Oncol. 1994;33(4):365-369.

33. Allison PD. Fixed Effects Regression Methods for Longitudinal Data Using SAS. Cary, NC: SAS Institute Inc.; 2005.

34. Allison PD, Christakis NA. Fixed-effects methods for the analysis of nonrepeated events. Sociol Methodol. 2006;36(1):155-172.

35. Lindström M. Invited commentary: social capital, social contexts, and depression. Am J Epidemiol. 2008; 167(10):1152-1154.

36. Stringhini S, Sabia S, Shipley M, et al. Association of socioeconomic position with health behaviors and mortality. JAMA. 2010;303(12):1159-1166.

37. Giordano GN, Lindström M. The impact of changes in different aspects of social capital and material conditions on self-rated health over time: a longitudinal cohort study. Soc Sci Med. 2010;70(5):700-710.

38. Kouvonen A, Oksanen T, Vahtera J, et al. Workplace social capital and smoking cessation: the Finnish Public Sector Study. Addiction. 2008;103(11):18571865 .

39. Lindström M, Hanson BS, Östergren P- O. Socioeconomic differences in leisure-time physical activity: the role of social participation and social capital in shaping health related behaviour. Soc Sci Med. 2001;52(3):441451.

40. Kawachi I, Berkman L. Social ties and mental health. J Urban Health. 2001;78(3):458-467.

41. Rogers E. Diffusion of Innovations. New York, NY: Free Press; 1983.

42. Fujiwara T, Kawachi I. Social capital and health: a study of adult twins in the U.S. Am J Prev Med. 2008; 35(2):139-144.

43. Ferlander $\mathrm{S}$. The importance of different forms of social capital for health. Acta Sociol. 2007;50(2):115128.

44. Pearce N, Checkoway H, Kriebel D. Bias in occupational epidemiology studies. Occup Environ Med. 2007;64(8):562-568.

45. Robins J. A new approach to causal inference in mortality studies with a sustained exposure periodapplication to control of the healthy worker survivor effect. Math Model. 1986;7(9-12):1393-1512.

46. Kivimäki M, Virtanen M, Elovainio M, Kouvonen A, Väänänen A, Vahtera J. Work stress in the etiology of coronary heart disease-a meta-analysis. Scand J Work Environ Health. 2006;32(6):431-442. 